\title{
Rupture uterus - incidence and management in a tertiary centre in Assam
}

\author{
Saswati Sanyal Choudhury, Bikash Choudhury, Gitanjali Deka \\ Correspondence: Dr Saswati Sanyal Choudhury, Associate Professor, Department of \\ Obstetrics and Gynaecology, FAA Medical College, Barpeta, Assam; Email - \\ saswatischoudhury@gmail.com
}

Distributed under Creative Commons Attribution-Share Alike 4.0 International.

\begin{abstract}
Objectives: The purpose of this study was to see the incidence of rupture uterus, the predisposing factors and the different modalities of management with outcome. Methodology: All patients of rupture uterus admitted during June 2011 to May 2012 were taken. The detailed history and clinical examination were done in a standard proforma. Results: Out of 14161 deliveries total number of cases of rupture uterus was 24 giving an incidence of 1 in 590 or $0.17 \%$. Twenty two (91.66\%) cases were unbooked and majority of them were para $1(62.5 \%)$ and in age group of 26-30 yrs $(45.83 \%)$. Post caesarean pregnancy was the dominant risk factors which was $41.66 \%$ followed by obstructed labour $(29.16 \%)$. Injudicious use of oxytocics in multipara was responsible for $12.5 \%$ cases. Twelve cases had been repaired, 2 cases had been repaired with internal iliac artery ligation and 8 cases had undergone subtotal hysterectomy with internal iliac artery ligation. The outcome of all postoperative cases was satisfactory except one patient died due to septicaemia. Conclusion: Rupture uterus is still a problem in this region. Post caesarean pregnancy is the commonest risk factor followed by obstructed labour.
\end{abstract}

Keywords: Rupture uterus, repair, subtotal hysterectomy, internal iliac artery ligation.

Modern obstetrics have virtually eradicated the problem of rupture uterus in developed countries but elimination process has just started in developing countries. Hence the rupture uterus and its sequelae are still hunting the minds of obstetricians in countries like India. The incidence varies from lin 2581 to 1 in $110^{1}$, 2. Out of different indications of obstetric hysterectomy rupture uterus is an important indication in presence of sepsis and presence of broad ligament haematoma with lateral rupture. Incidence of obstetric hysterectomy for different reasons varies from $0.0779 \%$ to $0.38 \%{ }^{3,4}$.

\section{Materials and Methods}

This study was carried out in the Department of Obstetrics and Gynaecology, Gauhati Medical College and Hospital, Guwahati for a period of one year from $1^{\text {st }}$ June 2011 to $31^{\text {st }}$ May 2012. Women of any age group referred from outside or admitted directly in the department presented with rupture uterus and managed surgically were included in this study. On receiving patient thorough history and clinical history was carried out and recorded in a standard proforma. Patient were resuscitated with intravenous fluids, antibiotics, cross

Received: $10^{\text {th }}$ June 2017. Accepted: $26^{\text {th }}$ June 2017.

Choudhury SS, Choudhury B, Deka G. Rupture uterus - incidence and management in a tertiary centre in Assam. The New Indian Journal of OBGYN. 2017; 4(1):77-80 
matched blood kept ready along with routine investigations and prepared for laparotomy with senior obstetricians. Depending on the condition of the rupture, age, parity and availability of blood appropriate surgical methods like repair of the wound or subtotal hysterectomy with or without internal iliac artery ligation were carried out under regional or general anaesthesia in consultation with anaesthesiologists. Data were collected in structured proforma and analyse in number and percentage.

\section{Results and observations}

Out of total 14,161 deliveries in the hospital during the period there were 24 cases of rupture uterus. Incidence of rupture was 1 in 590 or $0.17 \%$. There

Table 1: Age, Parity and Risk factors distribution of rupture uterus cases $(\mathrm{N}=24)$

\begin{tabular}{lll}
\hline \multicolumn{2}{l}{ Variables } & Number (\%) \\
\hline Age in & $<20$ & 0 \\
years & $20-25$ & $8(33.33 \%)$ \\
& $26-30$ & $11(45.83 \%)$ \\
Parity in & $>30$ & $5(20.83 \%)$ \\
number & 1 & 0 \\
& 2 & $15(62.5 \%)$ \\
& 3 & $6(25 \%)$ \\
& 4 & $2(8.33 \%)$ \\
Risk & $\geq 5$ & 0 \\
factors & Post caesarean pregnancy \\
for & Pbstructed labour & $1(4.16 \%)$ \\
rupture & Forceps delivery & $7(29.16 \%)$ \\
uterus & Multipara with oxytocics & $3(12.5 \%)$ \\
\hline
\end{tabular}

were only 2 booked cases and rest 22 cases were unbooked and percentage of unbooked cases was $91.66 \%$. Highest number of rupture uterus was seen in age group of 26 - 30years which was 11 out of $24(45.83 \%)$. It was observed that there was not a single case of rupture in primigravida. Maximum number of rupture uterus cases were seen in parity one (62.5\%). It was observed that post caesarean pregnancy is one of the commonest cause of rupture uterus which was $41.66 \%$ followed by obstructed labour. Use of oxytocics in multipara was responsible for rupture in $12.5 \%$ cases. One case of rupture uterus following application of forceps was referred from outside (table 1). It was observed that half of the cases were managed

Table 2: Surgical management of rupture uterus

\begin{tabular}{ll}
\hline Surgical management & No of cases $(\%)$ \\
\hline Subtotal hysterectomy (STH) & $2(8.33)$ \\
Repair and BL int. Iliac ligation & $2(8.33)$ \\
STH \& B/L Int. Iliac ligation & $8(33.33)$ \\
Only repair & $12(50)$ \\
Total & $24(100)$ \\
\hline
\end{tabular}

with repair only. Subtotal hysterectomy with bilateral internal iliac ligation was done in $33.33 \%$ cases. Only subtotal hysterectomy was done in 2 cases $(8.33 \%)$ and repair with bilateral internal iliac artery ligation was done 2 cases (8.33\%) (table 2). Success rate were 100\% in all type of surgery.

\section{Discussion}

Rupture uterus still comprises one of the obstetric emergencies in India. Incidence of rupture uterus is shown in the table 3 along with present study. A relatively high incidence of rupture uterus in this series may be due to bulk of referred cases from peripheral hospitals. Gauhati Medical College being a well developed tertiary hospital in lower Assam, all the critical cases were referred to GMCH leading to the higher incidence of rupture.

Incidence of booked cases is very low in rupture uterus cases and most of the patients were from rural background with low socio-economic status and high rate of illiteracy. Majority of cases in present study were unbooked which comparable with the study of Radhakrishnan ${ }^{8}$ from Delhi (91.66\% and $\left.80 \%\right)$. In the
Table 3: Incidence of rupture uterus in various study

\begin{tabular}{|c|c|c|c|}
\hline Authors & Year of study & $\begin{array}{ll}\text { No of } \\
\text { cases }\end{array}$ & Incidence \\
\hline Padhye SM $^{5}$ & 1985-2005 & 251 & $1: 1100$ \\
\hline Ahmadi $S$ et al ${ }^{1}$ & $1989-1997$ & 28 & $1: 2581$ \\
\hline Chatterjee S R et al ${ }^{6}$ & 1995- 2004 & 40 & $1: 273$ \\
\hline Sahu L ${ }^{7}$ & $1995-2004$ & 253 & $1: 346$ \\
\hline Present study & 2011-12 & 24 & $1: 590$ \\
\hline
\end{tabular}


present study majority of rupture uterus was seen 26-30 yrs age group (45.83\%) and is comparable with the findings of Mahapatra U $(46.6 \%)^{9}$.

In the present study incidence was highest with parity between 1-4 (95.83\%) which is comparable with Ehigieba $\mathrm{AE}^{10}$ (70.16\%). In the present study there was not a single case of rupture in primigravida and same is been shown by other studies except Ojenuwah ${ }^{11}$ where the incidence was $5.3 \%$ in primi.

In the present study, it was observed that post caesarean pregnancy is one of the commonest causes of rupture uterus which was $41.66 \%$. The incidence of scar rupture in this study is comparable to other studies like Sahu L (50.1\%) ${ }^{7}$, Sahin HG et al $(39.39 \%){ }^{12}$, Malik HS (53.39\%) ${ }^{13}$ and Zeteroglu S et al $(45 \%){ }^{14}$. Incidence of obstructed labour causing rupture uterus was $29.16 \%$. The incidence is found to be $26.47 \%$ in Sameera Khan study ${ }^{15}, 26.6 \%$ in the study of Radhakrishnan ${ }^{8}$ but was higher in Israq Dhaifalah ${ }^{16}$ (83\%) and Chuni $\mathrm{N}$ study ${ }^{17}$ (46.5\%). Oxytocin was found to be responsible for rupture in $12.5 \%$ cases in our study where as in Sameera Khan Study ${ }^{15}$ it was $32.35 \%$.

Surgical management in the form of repair was done in $50 \%$ cases in this study which is comparable with the study of Zeteroglu $\mathrm{S}^{14}$ (65\%), Sameera Khan ${ }^{15}$ (52.9\%), Sahu Latika ${ }^{7}$ ( 57.7\%) and S A Ojenuwah ( $50 \%)^{11}$. Subtotal hysterectomy was done in $8.33 \%$ cases which can be compared with the study of Sahu Latika ${ }^{7}$ which was $7.9 \%$. None of the patients had total hysterectomy in this study as in the studies of Sameera Khan ${ }^{15}$, Ojenuwah ${ }^{11}$ and Padhye SM ${ }^{5}$. Repair is safer and can be possible even in shock and causes less operative morbidity and less time consuming. Moreover hysterectomy at prime time of reproductive period causes a great psychological stress in these women and therefore repair with conservation of uterus is a better procedure. When patient is in a grave situation, Munro Kerr's advice is internal iliac artery ligation for controlling haemorrhage. But Boy in 1962 criticised repair of rent as mortality was very high with this procedure because of absorption of toxins as the infected uterus was left behind. In the present study one patient died on $4^{\text {th }}$ day after operation due to septicaemia after successful repair of the rent.

\section{Conclusion}

Rupture uterus is still a nightmare in developing country and lack of antenatal and intranatal care is the most important risk factor for this almost cent percent preventable complication of pregnancy and labour. Previous caesarean scar rupture is high and therefore primary caesarean section should be done with utmost care and in indicated cases only and not for trivial reasons like on request. Early involvement of senior obstetrician to deal with this complication will reduce severe maternal morbidity and mortality.

\section{Conflict of interest: None. Disclaimer: Nil.}

\section{References}

1.Ahmadi S, Nouira M, Bibi M. Uterine rupture of the unscarred uterus. About 28 cases. Gynecol Obstet Fertil. 2003; 31(9): 713-7.

2.Ofir K, Sheiner E, Levy A. Uterine rupture: Risk factors and pregnancy outcome, Am J Obstet Gynecol. 2003; 189: 1042-6.

3.Praneswari devi, R K Singh, Singh D. Emergency obstetric hysterectomy. J Obstet Gyneco India. 2004; 54: $343-5$.

4.Sinha H, Mishra M. Hysterectomy for obstetric emergency. J Obstet Gynecol India 2001; 51: 111-4.

5.Padhye SM. Rupture uterus in primigravida: morbidity and mortality.Kthmandu Univ Med J. 2007; 5(4): 492-6.

6.Chatterjee SR, Bhaduri S. Clinical analysis of 40 cases of uterine rupture at Durgapur Subdivisional Hospital: an observational study. J Indian Med Assoc. 2007; 105(9): $510-12$.

7.Sahu L. A 10 year analysis of uterine rupture at a teaching institution. J Obstet Gynaecol India. 2006; 56(6): 502-6.

8.Rashmi, Radhakrishnan G, Vaid NB, et al. Rupture uterus changing Indian scenario. J Indian Med Assoc. 2001; 99(11): 634-7.

9.Mahapatra U. Rupture of Gravid Uterus in secondary 
care hospital. Rural Surgery. 2005; 1(4): 10-11.

10.Ehigiegba AE, Adeyemo IS. Uterine rupture in labour: a continuing obstetric challenge in developing countriesthe Benin experience. J Med Biomed Research. 2006; 5(1): 44-50.

11.Ojenuwah SA, Olowosulu RO. Surgical management of Ruptured uterus in BIDA North Central Nigeria. Tropical Doctor. 2007; 37: 219-21.

12.Sahin HG, Kolusari A, Yildizhan R, Kurdoglu M, Adali E, Kamaci M. Uterine rupture: A twelve-year analysis. J Matern Fetal Neonatal Med. 2008: 21: 503-6.

13.Malik HS. Frequency, predisposing factors and fetomaternal outcome in uterine rupture. J Coll Physicians Surg Pak. 2006; 16: 472-5.

14.Zeteroglu S, Ustun Y, Engin-Ustun Y, Sahin HG, Kamaci M. Eight years' experience of uterine rupture cases. J Obstet Gynaecol. 2005; 25(5): 458-61.

15.Khan S, Parveen Z, Begum S, Alam I. Uterine rupture: a review of 34 cases at Ayub teaching hospital Abbottabad. 2002. [cited 2017 Jan 10]. Available from: http://www. ayubmed.edu.pk/JAMC/PAST/154/Sameera.htm
16.Dhaifalah I, Santavy J, Fingerova H. Uterine rupture during pregnancy and delivery among women attending the Al-thawra Hospital in Sana'A City Yemen Republic. Biomed Pap Med Fac Univ Palacky Olomouc Czech Repub. 2006; 150: 279-83.

17.Chuni N. Analysis of uterine rupture in a tertiary center in Eastern Nepal: lessons for obstetric care. J Obstet Gynaecol Res. 2006; 32(6): 574-9.

\section{Saswati Sanyal Choudhury ${ }^{1}$, Bikash Choudhury ${ }^{2}$,} Gitanjali Deka ${ }^{3}$

${ }^{1}$ Associate Professor, Department of Obstetrics and Gynaecology, FAA Medical College, Barpeta, Assam, India; ${ }^{2}$ Registrar, Department of Obstetrics and Gynaecology, Tezpur Medical College, Tezpur, Assam, India; ${ }^{3}$ Associate Professor, Department of Obstetrics and Gynaecology, Tezpur Medical College, Tezpur, Assam, India. 